Original article

\title{
The relationship between the quality of work life and sleep in nurses at the intensive care units of teaching hospitals in Mazandaran, Iran
}

\author{
Behzad Momeni ${ }^{1}$, Vida Shafipour ${ }^{2 *}$, Ravanbakhsh Esmaeili ${ }^{3}$, Jamshid Yazdani Charati ${ }^{4}$
}

(Received: 24 Nov 2015; Accepted: 20 Jan 2016)

\begin{abstract}
Background and Purpose: Stress has adverse effects on the quality of sleep and professional life in nurses engaged in intensive care units (ICUs). This study aimed to evaluate the relationship between the qualities of work life and sleep in nurses employed in the ICUs of Mazandaran province in Iran.

Methods: This cross-sectional, descriptive-correlational study was conducted on 180 nurses employed in the ICUs of teaching hospitals affiliated to Mazandaran University of Medical Sciences, Iran in 2015. Participants were selected via stratified random sampling. Data collection tools included demographic questionnaire, Walton's Quality of Work Life (QWL), and Pittsburgh Sleep Quality Index (PSQI). Data analysis was performed in SPSS V.18 using descriptive and inferential statistics (independent T-test, one-way ANOVA, Pearson's correlation-coefficient, and logistic regression analysis).

Results: In this study, ICU nurses were dissatisfied with most of the dimensions associated with the quality of work life. Moreover, 49 participants (27.2\%) had poor quality of work life, while 119 (66.1\%) and 12 cases (6.7\%) had moderate and high quality of work life, respectively. Also, 69 (38\%) and 111 nurses (61.7\%) were reported to have good and unfavorable sleep quality, respectively. A significant, inverse, linear correlation was observed between the quality of work life and sleep quality $(\mathrm{P}=0.012)$.

Conclusion: According to the results of this study, quality of work life and sleep quality were moderate and unfavorable in the majority of ICU nurses, respectively. Moreover, sleep quality had a significant correlation with the quality of work life.
\end{abstract}

Keywords: Intensive care unit (ICU), Nurse, Quality of work life, Sleep quality

\section{Introduction}

Healthcare organizations are predominantly concerned with the level of job satisfaction of the employees in order to enhance their performance and efficiency. Healthcare managements commonly investigate the outcomes to resolve organizational problems. Recently, the new concept of job satisfaction, also known as quality of work life, has been taken into account by healthcare managers who seek to promote the quality of human resources through comprehensive programs necessary for the enhancement of job satisfaction, recruitments and retention of employees (1-3). Improvement of the quality of work life in employees is of paramount importance in professions such as nursing. Nursing involves close contact with humans, which could influence different aspects of this profession (4-6).

Several studies have reported undesirable quality of work life in nurses. For instance, the findings

\footnotetext{
${ }^{1}$ Student Research Committee, MSc Student of Nursing, School of Nursing and Midwifery, Mazandaran University of Medical Sciences, Sari, Iran 2," Corresponding author: Department of Medical-Surgical Nursing, Nasibeh Nursing \& Midwifery Faculty, Mazandaran University of Medical Sciences, Sari, Iran. Email: vidashafipour@yahoo.com

${ }^{3}$ Department of Medical-Surgical Nursing, Nasibeh Nursing \& Midwifery Faculty, Mazandaran University of Medical Sciences, Sari, Iran

${ }^{4}$ Department of Biostatistics, Faculty of Health, Mazandaran University of Medical Sciences, Sari, Iran
} 
of Koshki et al. indicated that $16 \%$ and $82 \%$ of nurses had low and moderate quality of work life, respectively (7). Quality of work life cannot be attained and developed effectively unless assessed meticulously. This parameter directly affects the ability of healthcare organizations to provide appropriate medical services for different patients. According to the literature, factors such as workplace stress, physical workplace, worklife imbalance, and rotational working shifts could remarkably impact the quality of work life (8). Rotational working shifts have been shown to have adverse effects on the normal life and sleep patterns of nurses (9).

Medical team members, especially nurses engaged in intensive care units (ICUs), have high workload and insufficient resting time. Consequently, they may experience tremendous stress, which will intimately reduce the quality of sleep and work life in these healthcare professionals $(8,10,11)$. Sleep disorders are considered as a common problem in many professions. These disorders could negatively affect nursing performance and increase treatment costs, while decreasing the quality of life, health care, productivity and job satisfaction $(12,13)$. Various studies have indicated that $50 \%$ of nurses suffer from severe sleep disorders, which pose significant risk to the health of these individuals, as well as the quality of care for patients $(14,15)$.

Considering the importance of the quality of sleep and work life in the performance and health of nurses, poor quality of these two factors as denoted in previous research, and lack of relevant studies in Iran, this study aimed to evaluate the relationship between the quality of work life and sleep in nurses employed in the ICUs of teaching hospitals affiliated to Mazandaran University of Medical Sciences in Iran.

\section{Materials and Methods}

This cross-sectional, descriptive-correlational study was conducted on 180 nurses working in the ICUs of four teaching hospitals (Imam Khomeini Hospital, Mazandaran Heart Center, Avicenna Hospital, and Zare Burn Hospital) affiliated to
Mazandaran University of Medical Sciences in Sari city, Iran. Participants were selected via stratified random sampling during July-September 2015.

Inclusion criteria of the study were as follows: 1) willingness to participate; 2) employment in ICU; 3) having an associate's degree or higher academic education and 4) at least two years of clinical work experience. Exclusion criteria were the use of psychiatric and antidepressant medications and history of mental or sleep disorders.

Data collection tools included demographic questionnaire, Walton's Quality of Work Life (QWL), and Pittsburgh Sleep Quality Index (PSQI) $(1,10)$. QWL consists of 24 items scored based on a five-point Likert scale (score 1: very low, score 5: very high). General quality of work life was categorized into three main levels of low (score range: 24-55), moderate (score range: 5688), and high (score range: 88-120). QWL contains eight main scopes, as follows: adequate and fair compensation, safe and healthy working conditions, immediate opportunity to use and develop human capacities, opportunity for continued growth and security, social integration in the work organization, constitutionalization in the work organization, work and total life span, and social relevance of work life. Reliability of QWL has been confirmed in the study by Khaghanizadeh et al. using the Cronbach's alpha (0.89) (7).

In this study, PSQI was used to evaluate the quality of night sleep in nurses within the past month. This scale consists of 18 items; items 1-4 are open-ended, and items 5-18 are scored based on a four-point Likert scale. Validity of PSQI has been estimated at 0.85 using Cronbach's alpha in the study by Moradi et al. (10).

In order to assess the reliability of the questionnaires, they were completed by 15 nurses, which resulted in the Cronbach's alpha of 0.83 and 0.81 for PSQI and QWL, respectively. Before distributing the questionnaires among the participants, official permit was obtained from the Ethics Committee of Mazandaran University of Medical Sciences. Moreover, objectives of the study were explained to the nurses, and the participants were assured of confidentiality terms regarding 
their personal information.

Data analysis was performed in SPSS V.18 using descriptive (mean and standard deviation for quantitative variables and absolute, relative and cumulative frequency tables for qualitative variables) and inferential statistics (independent T-test, one-way ANOVA, Pearson's correlationcoefficient, and logistic regression analysis).

\section{Results}

In total, $180 \mathrm{ICU}$ nurses were enrolled in this study and completed the questionnaires. Among the participants, $21.1 \%$ and $78.9 \%$ were male and female, respectively with the mean age of $38.1 \pm 6.8$ years. The majority of the participants were within the age range of $26-55$ years, $33.9 \%$ were single, $60.6 \%$ were married, and $3.3 \%$ and $2.2 \%$ were divorced and widows/widowers, respectively.

The majority of the participants $(95.6 \%)$ had bachelor's degree, and 4.4\% had master's degree in nursing. ICU nurses accounted for $55.6 \%$ of the study population, while $27.8 \%$ and $16.7 \%$ were engaged in cardiac care units (CCUs) and dialysis sections, respectively. Among these nurses, $87.2 \%$ worked at rotational shifts, while $8 \%$ had fixed working shifts. Mean of work experience among our participants was $12.9 \pm 6.29$ years (range: $2-28$ years). In terms of organizational status, $1 \%$ of the participants were supervisors, $5 \%$ were matrons, and $88.9 \%$ were nurses. With regard to residential status, $55 \%$ of the participants were house owners, and $45 \%$ were tenants. Mean of night working shifts in these subjects was estimated at $6.1 \pm 2.15$ per month.

According to our findings, mean of total quality of work life in ICU nurses was $69.2 \pm 17.71$; as such, $27.2 \%$ of these individuals had low quality of work life, while $66.1 \%$ and $6.7 \%$ had moderate

Table 1. Levels of quality of work life in ICU nurses

\begin{tabular}{lcc}
\hline${ }^{*} \mathbf{Q W L}$ & Frequency $(\mathbf{N})$ & $\mathbf{\%}$ \\
\hline Low & 49 & 27.2 \\
\hline Moderate & 119 & 66.1 \\
\hline High & 12 & 6.7 \\
\hline Total & 180 & 100.0 \\
\hline
\end{tabular}

*QWL: Quality of work life and high work life quality, respectively (Table 1). Furthermore, the results of independent T-test indicated that low quality of work life was more prevalent among the nurses with more than five night shifts per month compared to those with five or fewer night shifts $(\mathrm{P}=0.0 .23)$.

Mean of overtime working hours was $39.6 \pm 16.46$ per month among our participants, and $61.7 \%$ of these nurses considered their income to be inadequate, while $31.1 \%$ and $7.2 \%$ reported the income status to be moderate and high, respectively. On the other hand, the results of one-way ANOVA were indicative of a significant correlation between overtime working hours and quality of work life $(\mathrm{P}<0.001)$, while the results of one-way ANOVA showed a significant relationship between the quality of work life and income status of nurses $(\mathrm{P}<0.001)$.

In this study, no significant correlations were observed between the quality of work life in nurses and variables such as gender $(\mathrm{P}=0.368)$, age $(\mathrm{P}=0.096)$, marital status $(\mathrm{P}=0.779)$, education level $(\mathrm{P}=0.686)$, and ward of employment $(\mathrm{P}=0.579)$.

Mean score of PSQI was $7.0 \pm 3.80$ for the study population, which indicated the quality of sleep quality to be favorable in $38 \%$ and unfavorable in $61.7 \%$ of the participants (Table 2). Moreover, the results of Chi-square revealed a significant relationship between the type of work shifts (fixed or rotational) and sleep quality in ICU nurses $(\mathrm{P}=0.005)$. According to the results of Pearson's correlation-coefficient, there was a significant, inverse, linear correlation between the quality of work life and sleep quality of the ICU nurses $(\mathrm{P}=0.012, \mathrm{r}=-0.188)$.

Regression analysis of the relationship between different dimensions of quality of work life and sleep quality was indicative of a significant

Table 2. Frequency of favorable $(\mathrm{PSQI} \leq 5)$ and poor sleep quality (PSQI $>5$ ) in ICU nurses

\begin{tabular}{lcc}
\hline Quality of Sleep & Frequency $(\mathbf{N})$ & $\mathbf{\%}$ \\
\hline Favorable & 69 & 38.3 \\
\hline Poor & 111 & 61.7 \\
\hline Total & 180 & 100 \\
\hline
\end{tabular}


Table 3. Predictors of relationships between dimensions of QWL and sleep quality based on multiple regressions

\begin{tabular}{|c|c|c|c|c|c|c|}
\hline QWL Dimensions & Coefficients (B) & Standard Error & $\operatorname{Exp}(\beta)$ & $95 \%$ & ce Interval & P-value \\
\hline Income Status & 0.844 & 0.303 & 2.327 & 1.258 & 4.215 & 0.001 \\
\hline Environment Security & 0.636 & 0.263 & 1.890 & 1.129 & 3.161 & 0.010 \\
\hline Growth and Safety & 0.558 & 0.276 & 0.573 & 0.334 & 0.982 & 0.040 \\
\hline
\end{tabular}

correlation between income status, environment security, and growth/safety with the quality of sleep among ICU nurses (Table 3).

\section{Discussion}

The findings of the present study were indicative of a significant relationship between the quality of work life and sleep quality in ICU nurses. As such, quality of work life was found to be inherent to the quality of sleep among these healthcare professionals. Furthermore, a significant correlation was observed between the dimensions of quality of work life (income status, environment security, and growth/safety) and quality of sleep in ICU nurses. Therefore, improvement of the aforementioned parameters at the workplace is likely to increase the quality of sleep among nurses.

According to the results of the current study, the majority of ICU nurses had moderate or low quality of work life. This is in line with the findings of Dehghan Nayeri et al. (16), which reported 41.9\% of nurses to have moderate quality of work life. However, the quality of work life was slightly higher in our research. Similarly, the results obtained by Dargahi et al. (2006) indicated that $74.5 \%$ of nurses were dissatisfied with their work life quality, while only $0.85 \%$ of these individuals were satisfied with this parameter (2). On the other hand, Azarang et al. (2012) reported that the majority of the studied nurses $(66.3 \%)$ had favorable work life quality (17). Based on the aforementioned studies, it could be inferred that the quality of work life is not at an acceptable level among nurses, and this level may vary depending on the ward of employment and its specific features.

The findings of the present study were indicative of no significant correlation between variables such as gender, age, marital status, education level, and ward of employment with the quality of work life in nurses. Similarly, Nayeri et al. (2008) reported no significant relationship between the quality of work life with the gender and marital status of nurses (16). On the other hand, the results obtained by Mogharab et al. (2013) revealed a positive significant correlation between the age and quality of work life among nurses (1). Moreover, they claimed that employees with more overtime working hours had lower quality of work life. It seems that lack of leisure time and fatigue due to high workload could adversely affect the quality of work life in nurses. This finding has been confirmed in another study by Khaghanizadeh et al. (2001) (18).

The results of the current study were indicative of a significant relationship between the quality of work life and income status of ICU nurses. Furthermore, it was observed that nurses aged above 40 years had the lowest quality of work life, which might be due to factors such as insufficient income, approximating retirement, job burnout, and failure to meet the expectations of the healthcare organization. According to one study conducted on the nurses in the U.S, income was the most important contributing factor to the promotion of quality of work life (19). In this regard, Littler (1999) demonstrated that factors such as payment cut and high job stress play a pivotal role in the dissatisfaction of nurses with the quality of work life (20).

In another research, Moradi et al. (2012) stated that observation of safety standards, occupational health programs, and income and job welfare played a key role in the promotion of the quality of work life in nurses (10). However, high income alone could not guarantee motivated workforce and high quality of work life. In this regard, design and management of the payment system are considered as significant determinants of quality of work life (17). In the present study, the majority of ICU nurses (61.7\%) were reported to have unfavorable quality of sleep. 
Substantial evidence suggests that most nurses have frequent complaints of sleep disorders $(15,21)$.

In another study, Nasiri et al. (2012) evaluated the mental health of nurses engaged in the ICUs of the teaching hospitals of Tehran and reported that most of these nurses suffered from variable degrees of sleep disorders and mental fatigue (21). On the other hand, the results obtained by Kageyama et al. (2001) reported the prevalence of insomnia in $29.9 \%$ of the studied nurses, while $23 \%$ of the nurses were found to use sleeping pills to treat sleep disorders. This is inconsistent with the findings of the present study (22). Furthermore, in the present study, the quality of sleep was observed to be higher in nurses working at fixed shifts compared to those with rotational shifts. Therefore, it could be concluded that working shifts may lead to undesirable consequences in the normal life and sleep patterns of ICU nurses. As such, variable shift schedules may disrupt the sleep-wake cycle and natural compatibility of individuals with the circadian rhythms (13).

In their study, Shao et al. (2010) assessed the sleep quality and quality of life in nurses on shift work and reported that $57 \%$ of these healthcare professionals had overall scores of at least five, which denoted the poor quality of sleep (23). Another study on the sleep quality and job satisfaction of 418 nurses reported a mean score of $7.3 \pm 3.56$ based on PSQI (24), which is consistent with the results of the present study.

According to the study by Mueck et al. (2005), which examined the effects of working shifts, rotational shifts were found to cause psychological and physiological problems in nurses, especially in those aged above 40 years (25). Drowsiness and poor attention in nurses during work shifts could have a negative impact on the performance of these professionals and patient outcomes. Considering the fact that sleep problems among nurses are commonly associated with their work shifts, nurses engaged in night shifts need to spend a few hours sleeping during the day in order to ensure the compensation of inadequate sleep (25).

According to one study conducted to evaluate the general health and sleep quality of nurses, there was a significant difference between the sleep quality of nurses with fixed and rotational work shifts. As such, favorable quality of sleep was reported in $40 \%$ of the nurses with fixed work shifts and $10 \%$ of those with rotational shifts (26). In the present study, mean score of QWL in nurses with favorable sleep quality was significantly higher compared to those with poor quality of sleep. Moreover, the results of Pearson's correlation-coefficient were indicative of a significant, inverse, linear relationship between the scores of quality of work life and sleep quality.

Given that higher scores in PSQI represent lower sleep quality, increased quality of sleep could be associated with higher quality of work life. In this regard, various investigations have revealed a significant correlation between the dimensions of quality of work life (income status, environment security, and growth/safety) and sleep quality in nurses. In other words, if employees are satisfied with their income, find their work environment secure, have the necessary opportunity and conditions for growth and promotion, and are provided with job security, their quality of sleep is likely to increase as a result of these parameters.

\section{Limitations}

One of the limitations of this study was the presence of uncontrollable factors, such as different life schedules, individual habits and work schedules, which could affect the resting time of nurses before working shifts or during the day after shifts, ultimately diminishing their quality of sleep and general health.

\section{Conclusion}

According to the results of this study, the majority of ICU nurses had moderate quality of work life and low sleep quality. Given the centrality of nurses in the prevention and treatment of diseases in healthcare organizations, as well as the pivotal role of quality of work life and sleep quality in the promotion of healthcare services in Iran, it is recommended that nursing managements be improved, incentives be presented, and management of nurses in healthcare units be modified. Owing to the development of the nursing science, extensive training should be 
implemented as to enhance the quality of work life and sleep in nurses, which requires further research in different clinical settings.

\section{Conflicts of interest}

None declared.

\section{Author's contributions}

VSH designed the study, provided the important suggestions for the improvement of the first draft, revised the pape, and supervised the study process. $\mathrm{BM}$ collected the data and wrote the paper. JYCH performed the statistical analysis and contributed to the study design. RE provided important suggestions for the improvement of the first draft. All the authors read and approved the manuscript.

\section{Acknowledgements}

This article was extracted from a student thesis with code number of IR.MAZUMS.REC.94.1436. Hereby, we extend our gratitude to the Research Deputy of Mazandaran University of Medical Sciences for the financial support of this study. We would also like to thank all the Nurses for assisting us in this research project.

\section{References}

1. Reyasi HR. Work life quality of nurses working in educational hospitals affiliated to Birjand university of medical sciences, 2012. Modern Care J 2013; 10(1):84-90 (Persian).

2. Dargahi H, Gharib MI, Goodarzi M. Quality of work life in nursing employees of Tehran university of medical sciences hospitals. Hayat 2007; 13(2):13-21 (Persian).

3. Cho YJ, Park H. Exploring the relationships among trust, employee satisfaction, and organizational commitment. Public Manag Rev 2011; 13(4):551-73.

4. Vanaki Z, Vagharseyyedin SA. Organizational commitment, work environment conditions, and life satisfaction among Iranian nurses. Nurs Health Sci 2009; 11(4):404-9 (Persian).

5. Cole DC, Robson LS, Lemieux-Charles L, McGuire W, Sicotte C, Champagne F. Quality of working life indicators in Canadian health care organization: a tool for healthy, health care workplaces? Occup Med 2005; 55(1):54-9.

6. Awosusi O. Assessment of quality of working-life of nurses in two tertiary hospitals in Ekiti State, Nigeria. Afr Res Rew 2010; 4(2):113-24.

7. Koshki MS, Arab M. Quality of working life and its relation with productivity of nurses performance in Shahid Beheshti university of medical sciences hospitals. J Sch Public Health Res 2013; 4(10):81-90 (Persian).

8. Almalki MJ, Fitzgerald G, Clark M. Quality of work life among primary health care nurses in the Jazan region, Saudi Arabia: a cross-sectional study. Hum Resour Health 2012; 10:30.

9. Solaimany M, Masoudi R, Sadeghy T, Bahrami N, Ghorban M, Hassanpoor A. General health and its association with sleep quality in two groups of nurses with and without shift working in educational centers of Iran university or medical sciences. J Shahrekord Univ Med Sci 2008; 10(3):70-5 (Persian).

10. Moradi F. Assessment the relationship between job stress, quality of sleep and fatigue among nurses in selected hospitals of Tehran, 2013. [Mastres Thesis]. Tehran, Iran: Tehran University of Medical Sciences, School of Nursing and Midwifery; 2013 (Persian).

11. Williams ES, Manwell LB, Konard TR, Linzer M. The relationship of organizational cultur, stress, satisfaction and burnout with physician reported error and suboptimal pation care: results from the MEMO study. Health Care Manage Rew 2007; 32(3):203-12.

12. Daley M, Morin CM, LeBlanc M, Gregoire JP, Savard J, Baillargeon L. Insomnia and its relationship to health-care utilization, work absenteeism, productivity and accidents. Sleep Med 2009; 10(4):427-38.

13. Baqeri HO, Shahabi Z, Ebrahimi HO, Alaeenejad F. The association between quality of sleep and health-related quality of life in nurses. Hayat 2006; 12(4):13-20 (Persian).

14. Chan FM. Factors associated with perceived sleep quality of nurses working on rotating shifts. J Clin Nurs 2008; 18(2):285-93.

15. .Rahimpoor F, Saeedi F, Fazli A, Mohammadi S. The relationship of sleep quality and general health in shift working nurses. Occup Med Q J 2013; 4(4):8-13 (Persian).

16. Dehghannyieri N, Salehi T, Asadinoughabi AA. Assessing the quality of work life, productivity of nurses and their relationship. Iran J Nurs Res 2008; 3(9):27-37 (Persian).

17. Azarang S, Yaghmaee F, Shiri M. Correlation dimensions of quality of work life of nurses and demographic 
characteristics. Iran J Nurs Res 2012; 7(27):18-24 (Persian).

18. Khaghanizadeh M, Ebadi A, Rahmani M. The study of relationship between job stress and quality of work life of nurses in military hospitals. J Mil Med 2008; 10(3):175-84 (Persian).

19. Smith T. Monograph on the internet. Nursing Work Life Satisfaction Survey. Calgary Health Region. Available at: URL: http://www.nurses.ab.ca; 2004.

20. Littler C. Downsizing distemper. Sydney: Morning Herald; 1999.

21. Nasiri-Ziba F, Bogheiri F. Mental health status of critical care nurses in teaching hospitals of Tehran. Cardiovascular Nurs J 2012; 1(4):6-12.

22. Kageyama T, Nishikido N, Kobayashi T, Oga J, Kawashima
M. Cross-sectional survey on risk factors for insomnia in Japanese female hospital nurses working rapidly rotating shift systems. J Hum Ergol 2001; 30(1-2):149-54.

23. Shao MF, Chou YC, Yeh MY, Tzeng WC. Sleep quality and quality of life in female shift-working nurses. J Adv Nurs 2010; 66(7):1565-72.

24. Karagozoglu S, Bingöl N. Sleep quality and job satisfaction of Turkish nurses. Nurs Outlook 2008; 56(6):298-307.

25. Muecke S. Effects of rotating night shifts: literature review. J Adv Nurs 2005; 50(4):433-9.

26. Ghaljaei F, Naderifar M, Ghaljeh M. Comparison of general health status and sleep quality between nurses with fixed working shifts and nurses with rotating working shifts. Zahedan J Res Med Sci 2010; 13(1):47-50 (Persian). 